\title{
Analysis of Health-Associated Phytochemical Compounds in Seven Hypoxis Species
}

\author{
Busie E. Nsibande*, Karl-Eric Gustavsson, Li-Hua Zhu \\ Department of Plant Breeding, Swedish University of Agricultural Sciences, Alnarp, Sweden \\ Email: *nsibandebusie@gmail.com
}

How to cite this paper: Nsibande, B.E., Gustavsson, K.-E. and Zhu, L.-H. (2018) Analysis of Health-Associated Phytochemical Compounds in Seven Hypoxis Species. American Journal of Plant Sciences, 9, 571-583.

https://doi.org/10.4236/ajps.2018.94044

Received: January 23, 2018

Accepted: March 4, 2018

Published: March 7, 2018

Copyright $\odot 2018$ by authors and Scientific Research Publishing Inc. This work is licensed under the Creative Commons Attribution International License (CC BY 4.0).

http://creativecommons.org/licenses/by/4.0/

\begin{abstract}
Some species of the genus Hypoxis within the Hypoxidaceae family are known to contain phenolic glycosides that have different clinical functions. In the African continent Hypoxis species are regarded as valuable medicinal plants that have been used for decades by traditionalists and natives to treat numerous ailments. The corms and rhizomes of the geophytes contain hypoxoside, a norlignan diglucoside, which is one of the important phytochemicals with medicinal functions found in Hypoxis. In this study corm extracts of seven species: $H$. acuminata, $H$. argentea, $H$. filiformis, $H$. gerrardii, $H$. hemerocallidea, $H$. iridifolia and $H$. parvifolia were analyzed for the presence of ellagic acid, total phenolic content (TPC) and hypoxoside. Extracts of $H$. iridifolia and $H$. gerardii had the highest levels of total phenolic content of $369.6 \mu \mathrm{g} / \mathrm{g}$ and $318.2 \mu \mathrm{g} / \mathrm{g}$, respectively, compared to the rest of the species. Hypoxoside was found to be present in corm extracts of all the species in varying proportions. $H$. gerrardii, $H$. argentea and $H$. filiformis had the highest relative hypoxoside content of $7.1 \%, 6.6 \%$ and $6.6 \%$, respectively. It is interesting to note that Hypoxis hemerocallidea, the most commonly used species for medicinal extracts contained a much lower level of hypoxoside than most of the other species. Our study included species that have not been previously analyzed for either TPC or hypoxoside presence such as $H$. filiformis and $H$. gerrardii, thus providing novel information regarding the medicinal status and biochemical compounds of these Hypoxis species.
\end{abstract}

\section{Keywords}

Hypoxis, Hypoxoside, Medicinal Plants, Total Phenolic Content

\section{Introduction}

Some species of the genus Hypoxis belonging to the Hypoxidaceae family [1] [2] [3] 
[4] are known to contain compounds of medicinal value, mainly phenolic glycosides [5]. Members of this family are distributed worldwide, but mainly in the Southern Hemisphere [3] and the Torrid Zone [5]. In southern Africa and other parts of the continent, species of Hypoxis are regarded as valuable medicinal plants that have been used for decades by traditionalists and natives to treat numerous ailments [6]. Appleton et al. [7] reported that twelve species of Hypoxis were used in southern Africa for medicinal purposes. The corms and rhizomes of the geophytes contain the chemical compound (E)-1,5-bis(3'-hydroxy-4'-0- $\beta$-D-glucopyranosylphenyl) pent-1-en-4-yne [8], also known as hypoxoside, a norlignan diglucoside which is the most important phytochemical found in Hypoxis [9] [10]. This compound was first isolated and characterized from $H$. obtusa by Marini-Betolo et al. [11] and Vinesi et al. [1], and later from $H$. rooperi (synonym $H$. hemerocallidea), $H$. acuminata, $H$. nitida, $H$. obtusa, $H$. rigidula, and H. latifolia, by Drewes et al. [9]. Hypoxoside together with the sterol beta-sitosterol, are believed to be the most important phytochemicals derived from $H$. hemerocallidea that are available in the market [12].

Extracts from Hypoxis corms or rhizomes, usually $H$. hemerocallidea, commonly known as African potato, are used in the pharmaceutical industry to make health powders, tablets, capsules and creams to treat various ailments that include benign prostate hypertrophy, arthritis, common colds, diabetes, skin problems, and rheumatism [13]. Corm extracts of $H$. hemerocallidea are also known to have anti-inflammatory, anti-neoplastic, antioxidant, antidiabetic and anti-infective properties [14]. The underground storage organs are seemingly the main source of hypoxoside. Bayley and Vanstaden [15] found that extracts from leaves, corms, and roots of nine-month old plants of $H$. hemerocallidea showed that the corm contained the highest concentration of the compound, followed by the roots, whilst the leaves had insignificant levels of it. Vinesi [1] found that the hypoxoside content in the leaves was negligible, and that the rhizomes contained $5.37 \%$ of the compound in H. obtusa. In the study carried out by Page and Vanstaden [16] on three types of tissue culture of $H$. hemerocallidea, it was found that only the root type cultures from corm explants contained hypoxoside. Katerere and Eloff [17] have also reported a distinct difference in the chemical composition between leaves and corms, and that leaf extracts showed a more complex composition compared to corm extracts whereas corm extracts contained phytosterols that were not present in leaf extracts. They thus concluded that for medicinal use, leaves could not be used as a substitute for corms.

Other health-associated phytochemical compounds have been reported in some species of Hypoxis, such as phenolic compounds in fresh corms of $H$. hemerocallidea [18]; sterols and sterolins from plant extracts of $H$. hemerocallidea [19]; glycosides of uncommon aglucones characterized by the Ph-C5-Ph skeleton in rhizomes of some African species [20], a geraniol glycoside, acuminoside from plant extracts of $H$. acuminata [21], two phenolic glycosides, aureaside A and aureaside B from rhizomes of $H$. aureus [5], the glucoside nyasoside from $H$. 
nyasica [22], interject in a derivative of nyasoside from rhizomes of $H$. interjecta and $H$. multiceps [23], the glycosides acuminoside, hypoxoside andnyasoside from whole plants of $H$. obtusa [24]; whereas in $H$. filiformis, ellagic acid, was reported to be present [25]. This latter claim was however refuted as being erroneous as according to a review by Hillis [26], no member of the monocotyledons contains ellagic acid.

The value and importance of Hypoxis species as medicinal plants is also based on the fact that hypoxoside cannot be easily produced synthetically, and thus making these species a very important source of the phytochemical [16]. Since isolation of hypoxoside on a large scale from natural sources is very difficult, efforts of preparing analogues of rooperol, a derivative of hypoxoside, with the intention of finding a compound that was much simpler but with the same or better activity as rooperol were not successful. However, it was possible to isolate the major constituents from the corms of $H$. hemerocallidea, hypoxoside, a pentenyne derivative, and rooperol, the active compound that is derived through hydrolysis of hypoxoside by the enzyme [18] [27]. Hypoxoside was first isolated and characterized from $H$. obtusa [11] and together with the sterol beta-sitosterol now form the main phytochemicals extracted from $H$. hemerocallidea that are on the market [19].

The purpose of this study was to identify and compare the level of some biochemical compounds present in some Hypoxis species, especially hypoxoside, the most important medicinal compound in this genus. H. hemerocallidea seems to be the main species that has been widely studied or used for its medicinal compounds, and very little research has been done on other species [28]. It has been noted that amateur traders assume that all Hypoxis species are African potato ( $H$. hemerocallidea) and as such are medicinal. An investigation made by Sathekge et al. [29] revealed that different Hypoxis species were harvested from the wild and sold as African potato. This indicates that some of the herbal remedies that are sold on the market contain hypoxoside extracts from different $\mathrm{Hy}^{-}$ poxis species, and not just $H$. hemerocallidea. Knowledge of the type of secondary metabolites that are present in Hypoxis species may not eliminate the practice, but will render more insight on their true medicinal value and assist with future commercial production where more suitable species with high hypoxoside content should be used.

\section{Materials and Methods}

\subsection{Plant Material}

Seven species of Hypoxis: $H$. acuminata Baker, $H$. argentea Harv. Ex Baker, $H$. filiformis Baker, $H$. gerrardii Baker, $H$. hemerocallidea Fisch and Ave-Lall, $H$. iridifolia Baker and $H$. parvifolia Baker were analyzed for the presence and levels of ellagic acid, total phenolics and hypoxoside. The plants were taken from the wild in different regions of Swaziland, identified at the National Herbarium and the corms planted in the greenhouse at the Swedish University of Agricultural 
Sciences, Alnarp. Corms from the plants that had been in the greenhouse for 2 4 years were harvested, thoroughly washed in running tap water after removing the roots, dried with tissue paper, cut into small cubes and stored at $-80^{\circ} \mathrm{C}$ until further use. Before analyses, the frozen samples were dried in a CoolSafe ${ }^{\mathrm{TM}}$ SCANVAC vacuum freeze-dryer for about $48 \mathrm{~h}$ until a constant weight was obtained and then ground into a fine powder using an ICA ${ }^{\circledR} \mathrm{A} 10$ basic grinding mill. All analyses had 3 biological replications and data were statistically analyzed using Minitab 16.

\subsection{Ellagic Acid Determination}

\subsubsection{Extraction}

For extraction of ellagic acid, $25 \mathrm{ml} \mathrm{70 \%} \mathrm{acetone} \mathrm{were} \mathrm{added} \mathrm{into} 1 \mathrm{~g}$ of lyophilized sample powder and placed on a shaker at $4^{\circ} \mathrm{C}$ over-night. Aliquots of 1.5 $\mathrm{ml}$ were centrifuged at $12,500 \mathrm{rpm}$ for $12 \mathrm{~min}$ and $1 \mathrm{ml}$ of the supernatant was removed and placed in heat tolerant tubes to which $1 \mathrm{ml} 4 \mathrm{M} \mathrm{HCl}$ was added. The samples were heated on a Techne DRI-Block ${ }^{\circledR} \mathrm{DB} .2 \mathrm{~A}$ heating block at $95^{\circ} \mathrm{C}$ for $4 \mathrm{~h}$ and cooled to room temperature. Thereafter, $1 \mathrm{ml}$ of extract was transferred into new tubes to which $7 \mathrm{ml}$ of $0.1 \% \mathrm{HCl}$ were added to adjust the acetone concentration in the samples to $8 \%$. Phenomerex Strata ${ }^{\otimes}$ C18-T SPE-Pak columns were mounted into vacuum apparatus, one for each sample. The SPE-Pak columns were conditioned by running $10 \mathrm{ml}$ methanol through each column twice. Columns were equilibrated by flushing with $5 \mathrm{ml} 0.1 \% \mathrm{HCl}$ twice. Samples were loaded onto the columns and allowed to run through; columns were then washed with $5 \mathrm{ml} 0.1 \% \mathrm{HCl}$. To elute ellagic acid molecules, $2.5 \mathrm{ml}$ methanol was run through the columns and the eluates collected in tubes. Eluates of $600 \mu \mathrm{l}$ were pipetted into HPLC vials for analysis.

\subsubsection{LC-Method}

The extracted samples were injected unto an Agilent 1260 HPLC (High Performance Liquid Chromatography)-system that consisted of two mobile phases: A-20 mM KH${ }_{2} \mathrm{PO}_{4}$ (Potassium dihydrogen phosphate), $\mathrm{pH} 2.3$ and methanol (proportion 97:3), and $\mathrm{B}-$ Acetonitril. The flow rate was $1.0 \mathrm{ml} / \mathrm{min}$, injection volume $1 \mu \mathrm{l}$ using the Phenomenex Kinetex PFP $(2.6 \mathrm{u}) 50 * 3$ column. Binary gradients were used: 0 min $100 \%$ A; $3.5 \min 75 \%$ A, 25\% B; $4 \min 75 \%$ A, 25\% B; $4.5 \mathrm{~min} 100 \% \mathrm{~A}$ and $6 \mathrm{~min} 100 \% \mathrm{~A}$. Ellagic acid was identified and quantified at $254 \mathrm{~nm}$ using Diode detector, by external standard ellagic acid (Sigma-Eldrich, USA) and by retention time and light spectrum.

\subsection{Determination of Total Phenolic Content}

\subsubsection{Extraction}

One gram of freeze-dried sample powder was placed in $50 \mathrm{ml}$ tube and suspended in $25 \mathrm{ml} \mathrm{70 \%}$ acetone with gentle shaking overnight at $4^{\circ} \mathrm{C}$. Aliquots of $1.5 \mathrm{ml}$ were taken from the raw extract and centrifuged at $12,500 \mathrm{rpm}$ for 12 min. The supernatant was diluted $50 \times$ with $70 \%$ acetone and used for the analysis. 


\subsubsection{Analysis}

The Folin-Ciocalteau's colometric method [30], with some modifications, was used for phenolic compound analysis. In order to calculate the concentrations of phenolic compounds in the samples, a standard curve was first made using a solution of $2 \mathrm{mg} / \mathrm{ml}$ chlorogenic acid in methanol with 5 concentrations: $0,10,25$, 50, 100 and $200 \mu \mathrm{g} / \mathrm{ml}$, diluted in 5\% ethanol (Figure 1). For the total phenolic analysis, $12 \mu \mathrm{l}$ of the diluted sample extracts or chlorogenic acid solutions were loaded directly into a TC-plate and mixed with $50 \mu 118.2$ Millipore water. Twelve $\mu \mathrm{l}$ Folin-Ciocalteau's reagent (SIGMA) was added and the mixture was allowed to react for $6 \mathrm{~min}$ before adding $125 \mu \mathrm{l}$ of $7 \%(\mathrm{w} / \mathrm{v}) \mathrm{Na}_{2} \mathrm{CO}_{2}$. The samples were left to stand at room temperature for $75 \mathrm{~min}$ before measuring the absorbance at $765 \mathrm{~nm}$ on the spectrophotometer. Total phenolic content (TPC) was expressed as chlorogenic acid equivalents in $\mu \mathrm{g} / \mathrm{g}$ of sample dry weight $(\mu \mathrm{g} / \mathrm{g}$ DW).

\subsection{Hypoxoside Determination}

\subsubsection{Extraction}

The presence of hypoxoside was determined using the same extracts obtained for total phenolics above ( $70 \%$ acetone). Aliquots of $1 \mathrm{ml}$ were taken from the raw sample extracts and centrifuged at $10,000 \mathrm{rpm}$ for $10 \mathrm{~min}$ and $600 \mu \mathrm{l}$ were pipetted into HPLC vials and run in the HPLC.

\subsubsection{LC-Method}

The extracted samples were analyzed with an Agilent 1260 HPLC-DAD-MS-ESI(-) using a binary gradient, eluent A: $0.1 \% \mathrm{HCOOH}$ and eluent $\mathrm{B}$ : Acetonitril. The eluents were mixed as follows: 0 min-95\% A, 5\% B; 5 min-95\% A, 5\% B; 25 $\min -74 \%$ A, $26 \%$ B; $35-\min 35 \%$ A, $65 \%$ B; 38-min $95 \%$ A, $5 \%$ B and $41-\min 95 \% \mathrm{~A}, 5 \% \mathrm{~B}$. The flow rate was $0.425 \mathrm{ml} / \mathrm{min}$, the injection time $1 \mu \mathrm{l}$

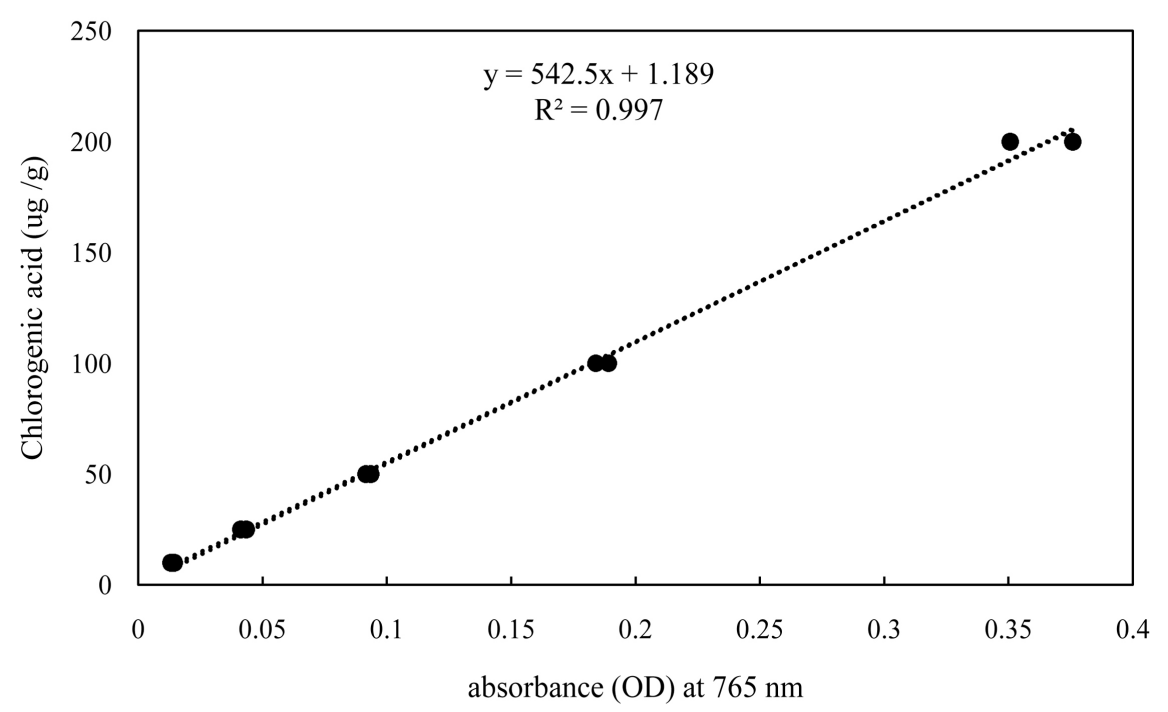

Figure 1. The standard curve of chlorogenic acid at different concentrations used as an equivalent standard for total phenolic content in different Hypoxis species. 
and column Phenomenex Luna C18(2) 100^2 (3 $\mu \mathrm{l})$. Hypoxoside molecules were identified with light spectra from Diode array detector and masses of molecular ion M/Z 605 and fragments 425, 245 with MS-ESi(-).

Hypoxoside content was expressed as the relative percentage of the compound obtained from the dry matter extracts of corms of the different species. This was derived from the area of hypoxoside molecules occupied by each sample extract in the chromatograph.

\section{Results and Discussion}

\subsection{Ellagic Acid}

No ellagic acid was detected in any of the samples of the species tested, however the chromatograms showed presence of other unidentified biochemical compounds that were similar in all the species but of varying amounts. All other species had peaks similar to the one obtained from $H$. filiformis (Figure 2). Yang et al. [25], reported that ellagic acid was found in H. filiformis, however, Hillis [26] reported that ellargic acid is not present in monocotyledons and that previous reports of its presence were probably "erroneous". To evaluate if ellargic acid is present in corms of Hypoxis, or not, we analyzed the 7 species. Our results partially confirm the report by Hillis, as the compound was not found in corm extracts of $H$. filiformis or in any of the other Hypoxis species that we tested, other plant parts were not tested for the presence of the compound. The light spectra images obtained from the highest peaks in the samples were compared with the light spectrum image of ellagic acid obtained from the standard sample.

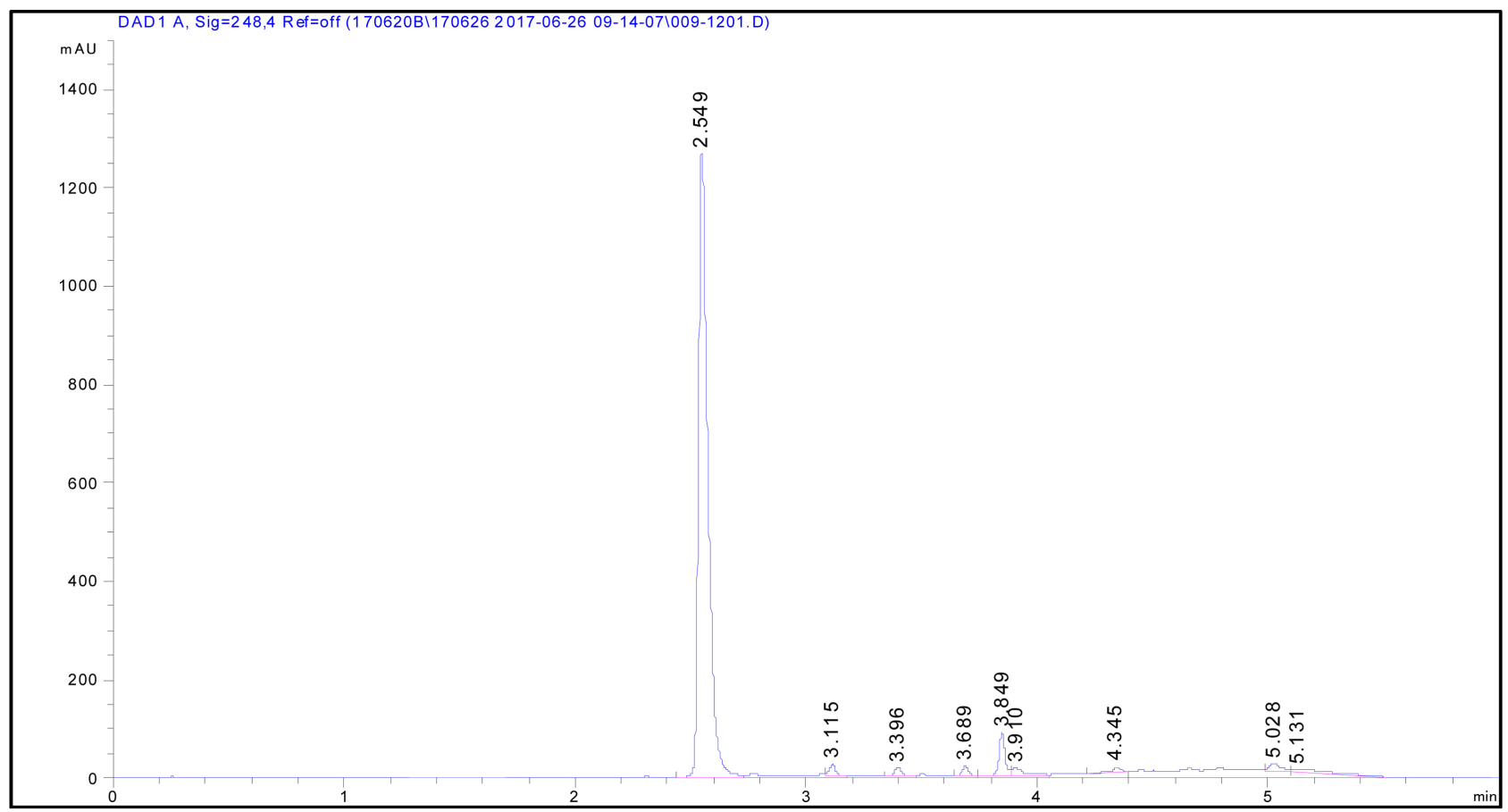

Figure 2. Chromatograph showing one big peak and several small peaks of unidentified compounds detected from the corm extract of $H$. filiformis. 
Comparison of the images showed that the light spectra images from the samples closely resembled that of ellagic acid but lacked a distinct feature that is present in ellagic acid (Figure 3) thus disqualifying the extracted compound from being ellagic acid. The peak obtained from our results could be any other type of secondary metabolite, which due to time limitation could not be verified. Sathekge et al. [29] found that corm extracts of $H$. acuminata, $H$. hemerocallidea, $H$. iridifolia and $H$. rigidula had secondary metabolites that were similar, when analyzed using TLC (Thin Layer Chromatography) and HPLC methods. Our findings also indicate that the corms of the seven species analyzed contain similar compounds, which however, could not be identified as the assay was based on the isolation and identification of ellagic acid.

\subsection{Total Phenolic Content (TPC)}

The results presented in Figure 4 show that the extracts from the freeze-dried corms of $H$. iridifolia and $H$. gerrardii had significantly higher levels of total phenolic compounds $(p=0.000)$ of $369.64 \mu \mathrm{g} / \mathrm{g}$ and $318.21 \mu \mathrm{g} / \mathrm{g}$, respectively, compared to the rest of the species. H. parvifolia had the second highest TPC $(254.39 \mu \mathrm{g} / \mathrm{g})$ whilst $H$. hemerocallidea $(204.56 \mu \mathrm{g} / \mathrm{g})$ extracts had a TPC content not different from that of $H$. parvifolia or $H$. filiformis $(172.84 \mu \mathrm{g} / \mathrm{g})$. H. argentea $(171.17 \mu \mathrm{g} / \mathrm{g})$ also showed a TPC content not significantly different from that of $H$. filiformis or $H$. acuminata. The corm extracts of $H$. acuminata had the least TPC of $134.79 \mu \mathrm{g} / \mathrm{g}$.

In order to make a general assessment of the common phenolic compounds present in the samples, extracts from two species that had the highest TPC, $H$. gerrardii and $H$. iridifolia plus one that had the lowest, $H$. acuminata, were run

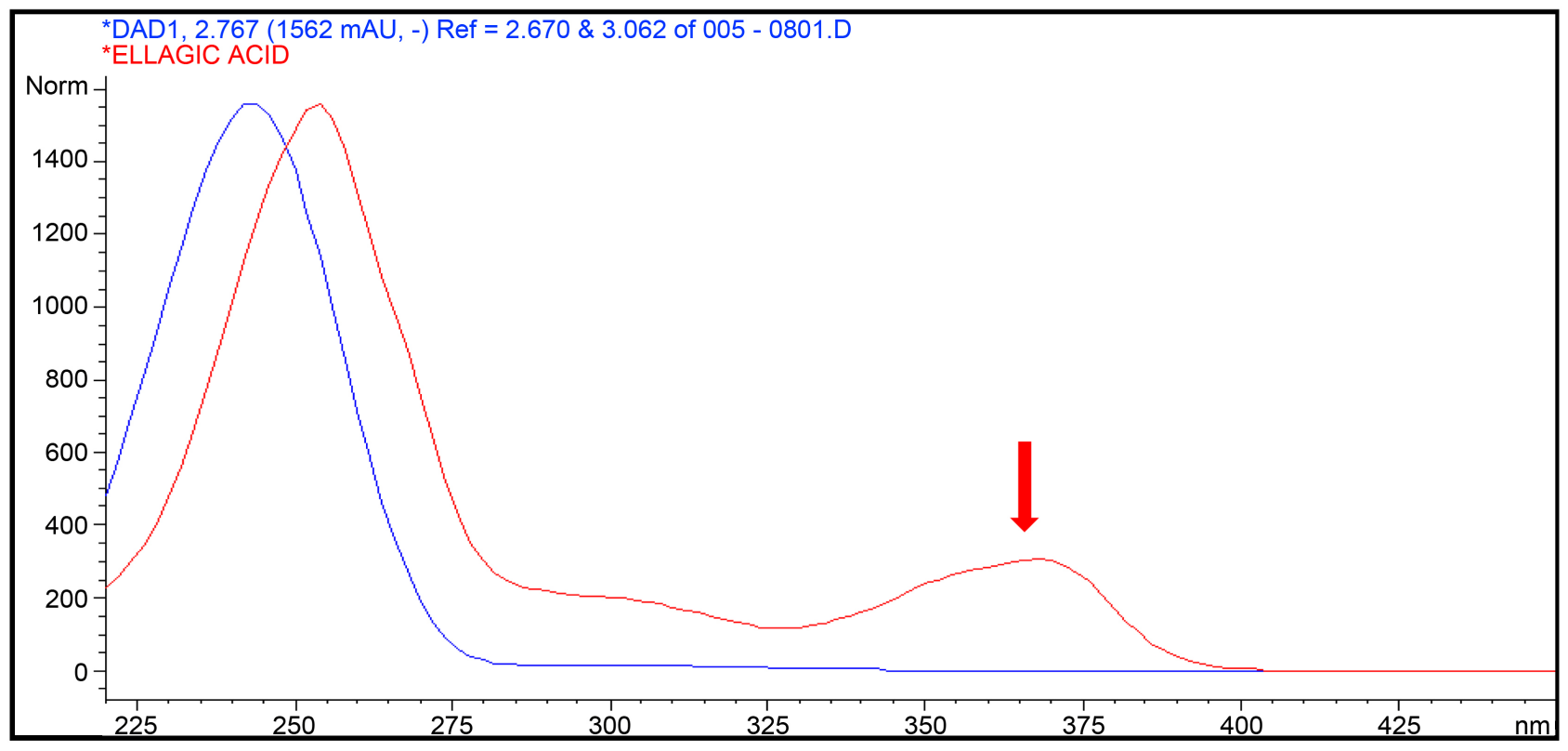

Figure 3. Light spectra images of ellagic acid from the ellagic acid standard (red) and an unidentified compound (blue) from the corm extract of $H$. filiformis (also found in abundance in all of the Hypoxis species tested). Arrow shows the special characteristic of ellagic acid that is not present in the other image. 


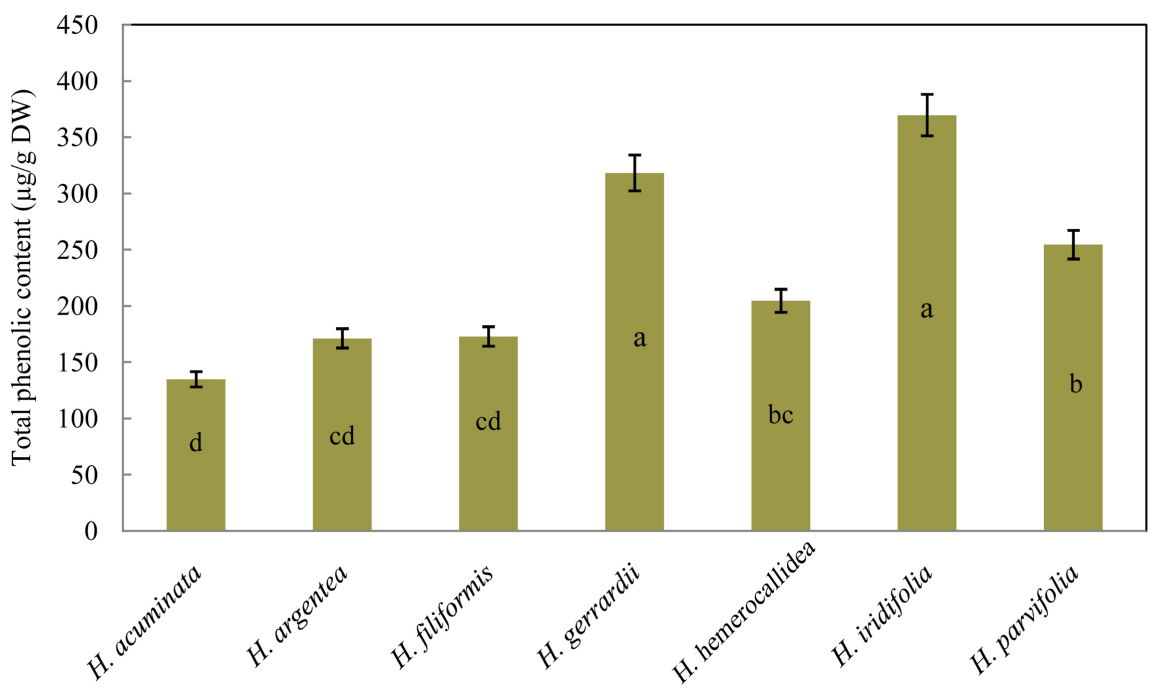

Figure 4. Total phenolic content in the corms of seven species of Hypoxis. Different letters in the bars indicate a significant difference in total phenolic content.

in the HPLC system using the LC-method described above for hypoxoside. In all three samples chlorogenic acid was found to be the most abundant, other phenols found were coumaric acid and flavanoids.

In corm extracts of $H$. hemerocallidea, Dzingirai et al. [31] obtained 0.268 $\mathrm{mg} / 100 \mathrm{mg}(2.68 \mu \mathrm{g} / \mathrm{g})$ dry mass of TPC standardized in gallic acid using the Folin Ciocalteu method, an amount much lower than that obtained for the same species in our analysis. They extracted the TPC from corms purchased from the market and used gallic acid as a standard, we used corms that had been grown in the greenhouse for some time, stored at $-80^{\circ} \mathrm{C}$ immediately after harvesting and used chlorogenic acid as a standard. These factors, including the extraction method as well as the growing conditions of the plants before the corms were harvested, may have an influence on the presence and content of phenols in the geophytes. Drewes and Khan [18] reported that $7.3 \%$ of the compounds they extracted from fresh corms of $H$. hemerocallidea were phenolic, whilst in this study, from the same species, $20.4 \%$ TPC was obtained from the lyophilized corms.

\subsection{Hypoxoside Content}

The norlignandiglucoside, hypoxoside, was found to be present in the freeze-dried samples of all the Hypoxis corm extracts analyzed. Hypoxoside $\left(\mathrm{C}_{29} \mathrm{H}_{34} \mathrm{O}_{14}\right)$ was analyzed using UPLC-DAD-MS(-) and identified by light spectrum(-) with two main peaks at 260 and $293 \mathrm{~nm}$, respectively (Figure 5), the mass spectra, MS-ESI(-) with the main molecular ion, $605.1 \mathrm{~g} / \mathrm{mol}$, and fragments 443.1 and $325.1 \mathrm{~g} / \mathrm{mol}$, respectively. These parameters combined indicated the highest likelihood of the compound as being hypoxoside.

Highly significant differences $(p=0.000)$ in relative hypoxoside content amongst the 7 Hypoxis species were observed (Figure 6). H. gerrardii, H. argentea 


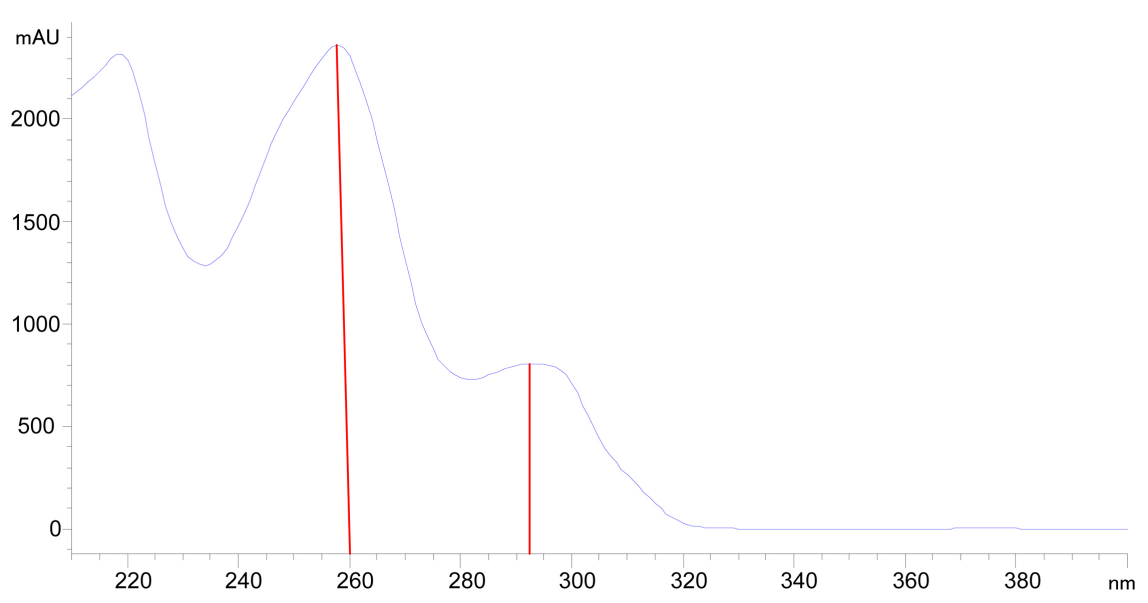

Figure 5. Light spectrum image of hypoxoside with two absorbance max at 260 and 293 nm, respectively.

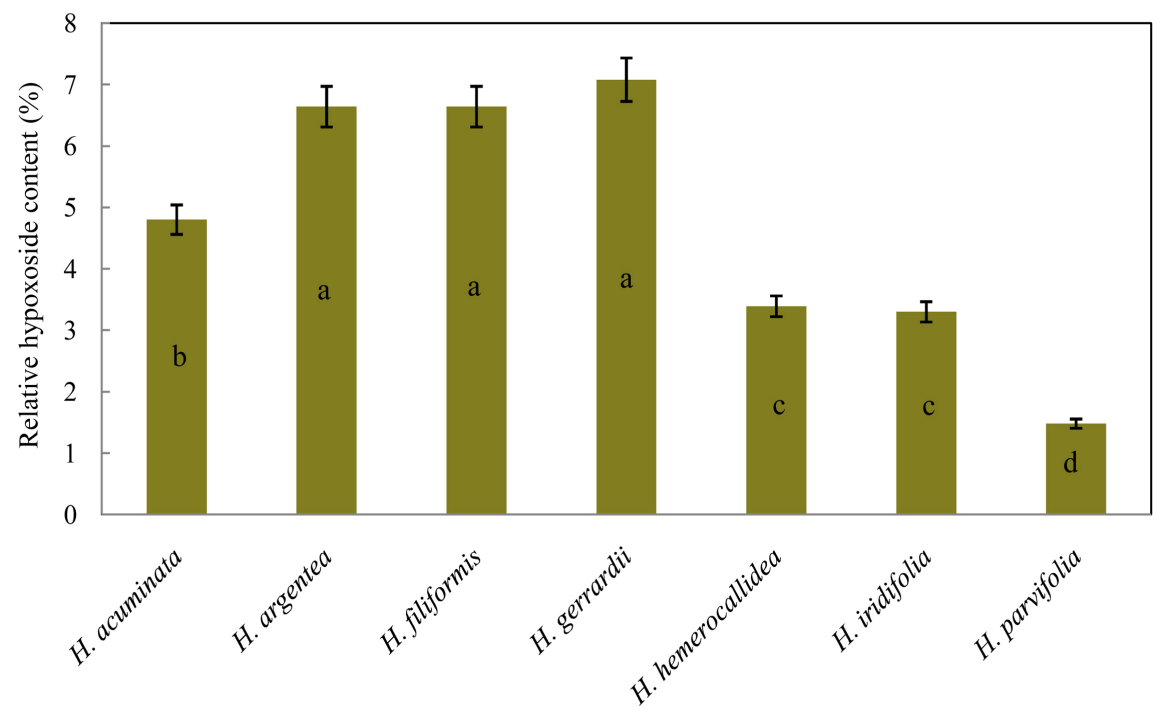

Figure 6. Hypoxoside content from the corm extracts of seven Hypoxis species. Different letters in the bars indicate significant differences in hypoxoside content among the species.

and $H$. filiformis had the highest relative hypoxoside contents of $7.1 \%, 6.6 \%$ and $6.6 \%$, respectively (Figure 6). The second highest hypoxoside content (4.8\%) was obtained from $H$. acuminata whilst $H$. hemerocallidea and $H$. iridifolia had similar proportions of $3.9 \%$ and $3.3 \%$, respectively. $H$. parvifolia had the least hypoxoside content with a relative content of $1.5 \%$. These results show a distinct difference in the amount of the compound found in each species. Whilst it was not possible to quantify the absolute hypoxoside content detected from the extracts due to the absence of a pure hypoxoside standard, the HPLC chromatograms gave a clear indication of its presence and proportion in the different species.

Hypoxoside seems to be one of the most common phenolic compounds present in Hypoxis species found in southern Africa. The compound has been isolated from at least 14 species including most of those used in this study. Pre- 
vious studies have shown that it is present in the corms of: $H$. acuminata, $H$. hemerocallidea, $H$. latifolia, $H$. nitida, $H$. obtusa, $H$. rigidula [9], $H$. angustifolia [1], H. nyasica [32], H. stellipillis, H. sobolifera var. sobolifera Boukes et al. [28], $H$. iridifolia [29]. Concentration of this diglucoside in the corms is reported to be seasonal but it is not clear when the highest yield can be obtained [9]. The yield from the corms of $H$. hemerocallidea has been reported to vary between 3.5 and $4.5 \%$ [9]. In chloroform extracts of $H$. hemerocallidea and $H$. stellipillis, Boukes et al. [28] found that the corms of $H$. hemerocallidea contained more hypoxoside $(12.27 \mu \mathrm{g} / 5 \mathrm{mg})$ than those of $H$. stellipillis $(7.93 \mu \mathrm{g} / 5 \mathrm{mg})$. They also found that in $H$. sobolifera var. sobolifera the hypoxoside content was negligible and could not be quantified. Lyophilized methanol extracts of $H$. hemerocallidea yielded the highest hypoxoside content $(10.82 \% / 100 \mathrm{~g})$ compared to sun-dried (1.29\%), shade-dried (2.79\%), or microwave-dried (5.85\%) extraction methods [10]. This may indicate that the type of extraction method used has an effect on the amount of the compound obtained.

Results from this study show that $H$. gerrardii, which also had the highest TPC amount, $H$. argentea and $H$. filiformis had higher hypoxoside contents than H. hemerocallidea; the species that has been extensively studied and whose corm extracts are widely used in the pharmaceutical industry. Vinesi [1] obtained a hypoxoside content of $5.37 \%$ from the rhizomes of $H$. obtusa, which was higher than that reported for $H$. hemerocallidea $(3.5 \%-4.5 \%)$. Whilst it may be true that other species have higher hypoxoside contents than $H$. hemerocallidea, it is unclear why this particular species has been used as the main source of the compound. Other aspects to be considered are the maturity of the corms at harvest, and the seasonal and geographical variations where the species grow. In this study the plants were collected from different agro-ecological regions and at different stages of maturity before the corms were planted in the greenhouse for a period ranging between 2 and 4 years, however for the analysis, the corms were harvested at the same time. As mentioned earlier, Drewes et al. [9], indicated that the concentration of hypoxoside in the corms is seasonal, and so far there are no reports indicating whether or not the season for achieving the highest yield has been established. Results from this study seem to disqualify the possibility that the observed variation in hypoxoside content among the different species were due to the variation in the period the plants were grown in the greenhouse. For instance, $H$. acuminata, $H$. argentea and $H$. filiformis are the species that had been in the greenhouse for the longest period, of these $H$. argentea and $H$. filiformis had the highest content of the compound together with $H$. gerrardii, which had been in the greenhouse for a relatively shorter period suggesting that the species do have different hypoxoside levels in the corms. The highest phenolic content was also obtained from $H$. gerrardii which had been grown in the greenhouse for two years.

\section{Conclusion}

Species of the genus Hypoxis may have similar secondary metabolites in varying 
amounts as shown by the seven species analyzed in this study, as well as previous studies by other researchers. However, this does not imply that all members of this genus possess medicinal properties of similar importance. What we have been able to establish is that the corms of the seven species: $H$. acuminata, $H$. argentea, $H$. filiformis, $H$. gerrardii, $H$. hemerocallidea, $H$. iridifolia and $H$. parvifolia do contain certain types of phenolic compounds that are most likely the same but in varying amounts, including hypoxoside, a bioactive phytochemical that has immune regulatory properties and is used in the composition of medicinal products in the pharmaceutical industry. In both total phenolic content and hypoxoside content, the amount of the compounds differed between the species; and in both instances, other species obtained higher amounts than $H$. hemerocallidea the species commonly used for making medicinal formulations. The variation obtained in both parameters cannot be attributed to the variation in the time of harvesting the corms as both high and low levels were obtained from species that had been grown in the greenhouse for a shorter or longer period. This suggests that there are actual differences in TPC and hypoxoside contents among the species. However, to rule out any doubt and the possibility of ontogenetic variation it is necessary that the plants are subjected to the same conditions including harvesting the corms at the same stage. Our study included species previously not analyzed for either total phenolic content or hypoxoside presence such as $H$. filiformis and $H$. gerrardii, thus providing novel information regarding the medicinal status and biochemical compounds of these Hypoxis species.

\section{Acknowledgements}

The authors would like to thank the National Herbarium Curator of the National Herbarium of Swaziland Mr Zacharia Dlamini for his assistance in identifying the Hypoxis species, the Swedish University of Agricultural Sciences for providing a good environment for this research, as well as project coordinator Dr Moneim Fatih and the Swedish international development agency for their financial support.

\section{References}

[1] Vinesi, P., et al. (1990) Plant-Regeneration and Hypoxoside Content in Hypoxis-Obtusa. Journal of Natural Products, 53, 196-199. https://doi.org/10.1021/np50067a031

[2] Singh, Y. (2007) Hypoxis (Hypoxidaceae) in Southern Africa: Taxonomic Notes. South African Journal of Botany, 73, 360-365. https://doi.org/10.1016/j.sajb.2007.02.001

[3] Kocyan, A., et al. (2011) Molecular Phylogenetics of Hypoxidaceae-Evidence from Plastid DNA Data and Inferences on Morphology and Biogeography. Molecular Phylogenetics and Evolution, 60, 122-136. https://doi.org/10.1016/j.ympev.2011.02.021

[4] Nsibande, B.E.B., et al. (2015) In Vitro Regeneration of Endangered Hypoxis Species. American Journal of Plant Sciences, 6, 2585-2595. 
https://doi.org/10.4236/ajps.2015.616261

[5] Cheng, Z.Q., et al. (2009) Two New Phenolic Glycosides from Hypoxis aurea Lour. Bulletin of the Korean Chemical Society, 30, 2446-2448.

https://doi.org/10.5012/bkcs.2009.30.10.2446

[6] Singh, Y. (1999) Hypoxis: Yellow Stars of Horticulture, Folk Remedies and Conventional Medicine. Veld \& Flora, 85, 123-125.

[7] Appleton, M.R., Ascough, G.D. and Staden, J.V. (2012) In Vitro Regeneration of Hypoxis colchicifolia Plantlets. South African Journal of Botany, 80, 10. https://doi.org/10.1016/j.sajb.2012.02.003

[8] Kruger, P.B., et al. (1994) Studies on Hypoxoside and Rooperol Analogues from Hypoxis rooperi and Hypoxis latifolia and Their Biotransformation in Man by Using High-Performance Liquid Chromatography with In-Line Sorption Enrichment and Diode-Array Detection. Journal of Chromatography B: Biomedical Sciences and Applications, 662, 71-78. https://doi.org/10.1016/0378-4347(94)00392-0

[9] Drewes, S.E., et al. (1984) Isolation of Hypoxoside from Hypoxis Rooperi and Synthesis of (E)-1,5-Bis(3',4'-dimethoxyphenyl)Pent-4-En-1-Yne. Phytochemistry, 23, 1313-1316. https://doi.org/10.1016/S0031-9422(00)80449-5

[10] Nair, V.D.P. and Kanfer, I. (2006) High-Performance Liquid Chromatographic Method for the Quantitative Determination of Hypoxoside in African Potato ( $\mathrm{Hy}$ poxis hemerocallidea) and in Commercial Products Containing the Plant Material and/or Its Extracts. Journal of Agricultural and Food Chemistry, 54, 2816-2821. https://doi.org/10.1021/jf052418s

[11] Bettolo, G.B.M., et al. (1982) Research on African Medicinal Plants-II: Hypoxoside, A New Glycoside of Uncommon Structure from Hypoxis Obtusa Busch. Tetrahedron, 38, 1683-1687. https://doi.org/10.1016/0040-4020(82)80147-6

[12] Nair, V.D.P. and Kanfer, I. (2008) Development of Dissolution Tests for the Quality Control of Complementary/Alternate and Traditional Medicines: Application to African Potato Products. Journal of Pharmacy and Pharmaceutical Sciences, 11, 35-44. https://doi.org/10.18433/J37G67

[13] Purushothaman Nair, V.D.P. (2006) Pharmaceutical Analysis and Drug Interaction Studies African Potato (Hypoxis hemerocallidea).

[14] Owira, P.M.O. and Ojewole, J.A.O. (2009) 'African Potato' (Hypoxis hemerocallidea Corm): A Plant-Medicine for Modern and 21st Century Diseases of Mankind? A Review. Phytotherapy Research, 23, 147-152. https://doi.org/10.1002/ptr.2595

[15] Bayley, A.D. and Vanstaden, J. (1990) Is the Corm the Site of Hypoxoside Biosynthesis in Hypoxis-Hemerocallidea. Plant Physiology and Biochemistry, 28, 691-695.

[16] Page, Y.M. and Vanstaden, J. (1987) Hypoxoside Production in Tissue-Cultures of Hypoxis-Rooperi. Plant Cell Tissue and Organ Culture, 9, 131-136. https://doi.org/10.1007/BF00044248

[17] Katerere, D.R. and Eloff, J.N. (2008) Anti-Bacterial and Anti-Oxidant Activity of Hypoxis hemerocallidea (Hypoxidaceae): Can Leaves Be Substituted for Corms as a Conservation Strategy? South African Journal of Botany, 74, 613-616. https://doi.org/10.1016/j.sajb.2008.02.011

[18] Drewes, S.E. and Khan, F. (2004) The African Potato (Hypoxis hemerocallidea): A Chemical-Historical Perspective. South African Journal of Science, 100, 425-430.

[19] Nair, V.D.P. and Kanfer, I. (2008) Sterols and Sterolins in Hypoxis hemerocallidea (African Potato). South African Journal of Science, 104, 322-324.

[20] Nicoletti, M., et al. (1992) Hypoxidaceae-Medicinal Uses and the Norlignan Con- 
stituents. Journal of Ethnopharmacology, 36, 95-101. https://doi.org/10.1016/0378-8741(92)90008-F

[21] Bredenkamp, M.W., Drewes, S.E. and Wentler, G.L. (1989) A Geraniol Glycoside from Hypoxis acuminata. Phytochemistry, 28, 263-265.

https://doi.org/10.1016/0031-9422(89)85053-8

[22] Marinibettolo, G.B., et al. (1985) Research on African Medicinal-Plants. 10. Glucosides of Hypoxis-Nyasica Bak the Structure of Nyasoside, a New Glucoside Biologically Related to Hypoxoside. Tetrahedron, 41, 665-670.

[23] Marinibettolo, G.B., et al. (1991) Research on African Medicinal-Plants. 27. Interjectin, a Derivative of Nyasicoside from Hypoxis-Interjecta and Hypoxis-Multiceps. Tetrahedron, 47, 6717-6724. https://doi.org/10.1016/S0040-4020(01)82323-1

[24] Msonthi, J.D., et al. (1990) A Phenolic Glycoside from Hypoxis obtusa. Phytochemistry, 29, 3977-3979. https://doi.org/10.1016/0031-9422(90)85384-R

[25] Yang, S.-W., et al. (1998) Three New Ellagic Acid Derivatives from the Bark of Eschweilera coriacea from the Suriname Rainforest. Journal of Natural Products, 61, 901-906. https://doi.org/10.1021/np980046u

[26] Hillis, W.E. (2014) Wood Extractives and Their Significance to the Pulp and Paper Industries. Elsevier Science, Amsterdam.

[27] Drewes, S.E., et al. (2008) Hypoxis hemerocallidea-Not Merely a Cure for Benign Prostate Hyperplasia. Journal of Ethnopharmacology, 119, 593-598.

https://doi.org/10.1016/j.jep.2008.05.027

[28] Boukes, G.J., van de Venter, M. and Oosthuizen, V. (2008) Quantitative and Qualitative Analysis of Sterols/Sterolins and Hypoxoside Contents of Three Hypoxis (African Potato) spp. African Journal of Biotechnology, 7, 1624-1629. https://doi.org/10.5897/AJB08.218

[29] Sathekge, N.R., Kritzinger, Q. and Prinsloo, G. (2010) Comparison of Secondary Metabolite Content and Antimicrobial Activity of Four Hypoxis Species Used in Traditional Medicine. South African Journal of Botany, 76, 403-403. https://doi.org/10.1016/j.sajb.2010.02.044

[30] Dewanto, V., et al. (2002) Thermal Processing Enhances the Nutritional Value of Tomatoes by Increasing Total Antioxidant Activity. Journal of Agricultural and Food Chemistry, 50, 3010-3014. https://doi.org/10.1021/jf0115589

[31] Dzingirai, B., et al. (2007) Phenolic Content and Phospholipids Peroxidation Inhibition by Methanolic Extracts of Two Medicinal Plants: Elionurus muticus and Hypoxis hemerocallidea. African Journal of Biochemistry Research, 1, 137-141.

[32] Betto, P., Gabriele, R. and Galeffi, C. (1992) Determination of the Norlignan Glucosides of Hypoxidaceae by High-Performance Liquid-Chromatography. Journal of Chromatography, 594, 131-135. https://doi.org/10.1016/0021-9673(92)80321-K 